\title{
The ontogeny of cultural learning Michael Tomasello
}

\begin{abstract}
All primates engage in one or another form of social learning. Humans engage in cultural learning. From very early in ontogeny human infants and young children do not just learn useful things from others, they conform to others in order to affiliate with them and to identify with the cultural group. The cultural group normatively expects such conformity, and adults actively instruct children so as to ensure it. Young children learn from this instruction how the world is viewed and how it works in their culture. These special forms of cultural learning enable powerful and species-unique processes of cumulative cultural evolution.
\end{abstract}

\section{Address}

Max Planck Institute for Evolutionary Anthropology, Deutscher Platz 6, D-04105 Leipzig, Germany

Corresponding author: Tomasello, Michael (tomas@eva.mpg.de)

\author{
Current Opinion in Psychology 2016, 8:1-4 \\ This review comes from a themed issue on Culture \\ Edited by Michele J Gelfand and Yoshihisa Kashima \\ For a complete overview see the Issue and the Editorial \\ Available online 25th September 2015 \\ http://dx.doi.org/10.1016/j.copsyc.2015.09.008 \\ 2352-250X/C 2015 Elsevier Ltd. All rights reserved.
}

Research in the past two decades has established that a number of different animal species engage in one or another form of cultural transmission based on one or another form of social learning. This includes most prominently humans' nearest primate relatives, chimpanzees [1]. But human cultural transmission is clearly different. Human cultural artifacts and practices accumulate modifications over time based on the so-called 'ratchet effect', in which an individual invention (e.g., an arrow made by sharpening a stick) is copied relatively faithfully by almost everyone in the group, and this modification stays in place until another individual makes a further modification (e.g., feathers on the arrow to improve flight), and so on cumulatively across generations [2]. Each cultural artifact or practice thus has its own unique cultural history.

Cumulative cultural evolution based on the ratchet effect requires a unique individual psychology. Individuals need to be equipped not just with general skills of social learning, but with more specialized skills of cultural learning. These are, most basically: [1] skills of imitative learning - and a strong conformist tendency — that enable an especially faithful reproduction of cultural practices by young children; and [2] adult teaching of children and, critically, a special sensitivity of children to glean from this pedagogy generalizable cultural knowledge.

\section{Imitative learning}

Human children and their nearest primate relatives share many processes of social learning. For example, human infants and the infants of both chimpanzees and rhesus monkeys mimic the mouth movements of a demonstrator from soon after birth. In addition, slightly older human infants and the infants of other primate species engage in so-called emulation learning in which the infant sees a physical transformation in the environment caused by the action of another, and they then employ their own individual strategies to reproduce that transformation. And chimpanzees have been shown to actually copy the intentional structure of another's action, for instance, by producing the full instrumental action even when they have only seen a failed attempt, and reproducing the intentional actions of others while simultaneously ignoring non-intentional accidents. What has been called chimpanzee 'culture', which is not cumulative, is based on social learning processes of these kinds $\left(\left[3^{\bullet \bullet}\right]\right.$, for a review).

Recent research has demonstrated some additional processes of imitative learning that seem to be unique to the human species. Generally, a consistent finding in comparative studies is that human children are much more concerned than are other great apes to copy the exact actions of others, including arbitrary gestures, conventions, and rituals (see [4], for a review). Indeed, this tendency is so strong that some researchers have even coined the term 'ritual stance' to capture the fact that when children do not see a clear goal to an actor's action, they imitate even more precisely than if they do see a goal - presumably because the lack of a goal signals a noninstrumental function for the action, which therefore (given that it is being demonstrated) may be of cultural importance (e.g., [5,6]). Also tellingly, human children, but not great apes, copy even irrelevant parts of an action sequence in acts of so-called 'overimitation' ([7]; see also [8]). And most tellingly of all, human children, but not great apes, conform to others even in situations when they have to override a previously successful strategy to do so, so-called 'strong conformity' $\left[9^{\bullet}, 10^{\bullet \bullet}\right] .{ }^{1}$ Social imitation

\footnotetext{
${ }^{1}$ There is one study suggesting that chimpanzees also conform even when they have an already effective method [ $\left.11^{\circ}\right]$, but closer inspection of the data shows that only one of many individual subjects reliably switched its method of tool use to match that of others.
} 
(including over-imitation and the ritual stance) and strong conformity are not so much social learning strategies for increasing personal success in problem-solving situations, but more social strategies for aligning oneself with others so as to show one's affiliation and group identity with them $\left[12^{\bullet \bullet}\right]$. An interesting finding in this regard is that human infants will preferentially imitate individuals who speak their language, presumably ingroup members, over individuals who speak a different language $\left[13^{\circ}\right]$.

Young children are so concerned with conformity that they will even enforce it on others, even when they themselves are not affected. For example, after children learn that on this table we play the game this way and on that table we play it another way, if a puppet then plays the game the wrong way on the wrong table, they intervene and stop him [14]. In such interventions young children frequently use generic normative language such as 'You can't do it like that!' or 'That's the wrong way!', suggesting that nonconformity is somehow not compatible with our mutually known normative ideals of good conduct. Interestingly, when actors violate conventional norms, 3-year-olds admonish them more often if they are in-group rather than out-group members, presumably because in-group members should know better and be more committed to how 'we' do it $\left[15^{\circ}, 16^{\circ}\right]$.

Although experimental evidence is sparse, by all indications humans in all cultures engage in imitative learning and normative conformity. What little experimental evidence we have for children suggests that it emerges at the same young age in infancy in all human cultures. Thus, Callaghan et al. $\left[17^{\circ}\right]$ found that in the most basic skills of imitative learning one-year-old children growing up in three very different cultural settings (including two small-scale, non-literate cultures) all manifest these skills at similar ages. Further, Nielsen and Tomaselli ([18 $\left.{ }^{\circ}\right]$; see also [19]) found that children in a small-scale African culture 'overimitate' in the same basic way as children from a larger industrialized culture, presumably for similar reasons. This all makes sense as the most basic skills of imitative learning are not imparted by culture (contra [20]), but rather they make the evolution and acquisition of culture possible in the first place.

The overall point is that human children are not just imitatively learning actions that will be useful to them instrumentally, but rather they are imitating the precise actions of other individuals, even when these are irrelevant to the goal, in order to affiliate with others in the group. In general, young children are conforming to cultural conventions so as to fit in with the normative expectations of the group as a whole, and even making sure that others in the group follow convention as well by normatively enforcing conformity on them. Imitative learning thus reflects not only young children's need to acquire instrumentally useful information, but also their strong tendency to conform to the normative expectations of their cultural group.

\section{Instructed learning}

Among primates, only humans actively instruct their young [21]. Moreover, recent evidence suggests that young children are evolutionarily prepared to receive such instruction, as explicated, for example, in the theory of natural pedagogy $\left[22^{\bullet \bullet}\right]$. A new insight emanating from this theory is that when adults are instructing they are attempting to convey generic, not episodic, information. Thus, an adult might communicate to a child that there is a nut on the ground that she might want to eat, but, in another context, the adult might attempt to teach the child that nuts like these are typically found under trees like these (e.g., 'Chestnuts grow on these kinds of trees'). Csibra and Gergely $\left[22^{\circ}\right]$ have emphasized that adults in all cultures communicate in this generic mode at least some of the time with their children in instructional contexts (especially socially crucial information like kinship status and how to behave in public; see also [23]), and, as far as we know, no other animal species communicates generic information of this kind at all. In a recent study Butler and Markman [ $24^{\bullet \bullet}$ ] found that when adults instruct a child about a novel artifact by demonstrating how it works with pedagogical cues, the child is much more likely to generalize this information to novel objects of the same type than if they see that same demonstration not aimed at them pedagogically (see also [25]). A plausible interpretation is that children trust pedagogical communication and generalize it to new items because they see its generic formulation as coming from the cultural knowledge of their social group, with the instructor acting as a kind of authoritative representative. When the adult says that 'Chestnuts grow on these kinds of trees' she is not giving her opinion but rather imparting authoritatively an objective fact about the world as 'we' know it.

Interestingly, recent research has also found that young children themselves engage in instruction at a much younger age than previously thought. Thus, some evidence for this is apparent in the studies of so-called 'transmission chains', in which young children learn something and then teach another (and then another down the chain; e.g., $[26,27])$. In addition, in the studies of norm enforcement cited above (e.g., [14]), in many cases when 3-year-old children corrected norm violators (e.g., 'No, it doesn't work like that'), they continued by instructing the violator about how to do it properly. This instruction quite often was formulated in generic language as well, for example, 'These things go there!' And so, the two main ways that young children use generic language themselves are in instructing others pedagogically in generalized cultural knowledge and in enforcing 
the norms of behavior formulated by the cultural group (see $\left.\left[28^{\circ}\right]\right)$. This lends support to the characterization of pedagogical learning as cultural learning in the sense that its authority emanates from the cultural group and its institutions, as larger and objective realities that predated the child's arrival on the scene. Indeed, this authority is so strong, that if a child is instructed in how to use a novel artifact (that has several possible functions), they tend to stick with that function almost exclusively and so ignore its other interesting functions (much more than if left to explore it on their own without instruction; [29 $\left.{ }^{\circ}\right]$ ).

The significance of instructed or pedagogical learning in human evolution cannot be overstated. Cumulative cultural evolution is only possible because all individuals of a particular generation mostly learn the same thing from their elders, and so this is reliable and stable over time for all individuals - which sets the stage for any of them to potentially innovate. Obviously, when adults normatively expect children to learn, and they enforce these normative expectations, this creates precisely the kind of cultural ratchet that keeps cultural knowledge and practices stable over time until a novel innovation occurs. There may be considerable variation in how instruction happens in different cultures, varying from the explicit verbal instruction in generic normative language of Western educational systems to the normative expectations embodied in adults' 'guided participation' of children in more traditional small-scale societies (e.g., [30]). But some process in which adults normatively expect children to learn is a necessary component in the way that human cultures persist and evolve in the ways that they do.

\section{Conclusions and directions for future research}

Despite the presence of something like culture in many animal species, outside of the human species there is nothing like cumulative cultural evolution. The individual psychology needed to support this process is the kind of faithful transmission represented by social imitation and strong conformity, on the one hand, and special skills and inclinations of instruction by adults and instructed learning by children, on the other hand. These skills emerge in human children between one and three years of age and they are demonstrably absent in other animal species. It is possible that there are cross-cultural differences in human children's cultural learning, but so far, despite some documented differences in teaching styles across cultures, research suggests that both strong conformity and instructed learning are human universals.

Nevertheless, the most urgent need in the field currently is more cross-cultural research not only on learning contexts in which children experience their culture, but also if, as a result of those experiences, young children develop different skills of cultural learning. A systematic crosscultural approach to this question is sorely needed.

\section{References and recommended reading}

Papers of particular interest, published within the period of review, have been highlighted as:

- of special interest

$\bullet$ of outstanding interest

1. Mesoudi A: Cultural evolution: integrating psychology, evolution and culture. Curr Opin Psychol 2016, 8:15-21.

2. Tomasello M, Kruger A, Ratner H: Cultural learning. Behav Brain Sci 1993, 16:495-552 (Target Article).

3. Tomasello M: Human culture in evolutionary perspective. In

-. Advances in Culture and Psychology. Edited by Gelfand M. Oxford: Oxford U. Press; 2011.

Review of research on great apes' and human children's social and cultural learning.

4. Tennie C, Call J, Tomasello M: Ratcheting up the ratchet: on the evolution of cumulative culture. Philos Trans R Soc B 2009, 364:2405-2415.

5. Herrmann P, Legare C, Harris P, Whitehouse H: Stick to the script: the effect of witnessing multiple actors on children's imitation. Cognition 2013, 129:536-543.

6. Watson-Jones R, Legare C, Whitehouse H, Clegg J: Taskspecific effects of ostracism on imitation in early childhood. Evol Hum Behav 2014, 35:204-210.

7. Horner V, Whiten A: Causal knowledge and imitation-emulation switching in chimpanzees (Pan troglodytes) and children (Homo sapiens). Anim Cogn 2005, 8:164-181.

8. Lyons DE, Young AG, Frank C, Keil FC: The hidden structure of overimitation. Proc Natl Acad Sci U S A 2007, 104:19751-19756.

9. Haun DBM, Tomasello M: Conformity to peer pressure in - $\quad$ preschool children. Child Dev 2011, 82:1759-1767.

Even when children know better they conform to the groups judgment, especially when their response in made publicly.

10. Haun D, Tomasello M: Great apes stick with what they know; -• children conform to others. Psychol Sci 2014, 25:2160-2167. Even two-year-old children conform to the majority and even when they know better. But chimpanzees do not; they stick with what they know from their own experience and ignore the way that others are doing something.

11. Whiten $A$ : The second inheritance system of chimpanzees and - humans. Nature 2005, 437:52-55.

Review emphasizing similarities in cultural transmission between humans and chimpanzees.

12. Over H, Carpenter M: The social side of imitation. Child Dev -. Perspect 2013, 7:6-11.

Review of research showing that children often imitate in order to affiliate with others and identify with the social group.

13. Buttelmann D, Zmyj N, Daum MM, Carpenter M: Selective - imitation of in-group over out-group members in 14-monthold infants. Child Dev 2013, 84:422-428.

Even young infants prefer to imitate an in-group over an out-group member.

14. Rakoczy H, Brosche N, Warneken F, Tomasello M: Young children's understanding of the context relativity of normative rules in conventional games. Br J Dev Psychol 2009, 27:445-456.

15. Schmidt MFH, Rakoczy H, Tomasello M: Young children

- $\quad$ attribute normativity to novel actions without pedagogy or normative language. Dev Sci 2011, 14:530-539.

Children assume that intentional actions they see, especially those performed on an artifact, are normatively prescribed by the culture.

16. Schmidt M, Rakoczy H, Tomasello M: Young children enforce - social norms selectively depending on the violator's group affiliation. Cognition 2012, 124:325-333.

Children enforce conformity to conventional norms more on in-group than on out-group members.

17. Callaghan T, Moll H, Rakoczy H, Warneken F, Liszkowski U,

- Behne T, Tomasello M: Early social cognition in three cultural contexts. Monogr Soc Res Child Dev 2011, 76:1-142.

(Among other findings) One-year-olds in all cultures imitatively learn from others in similar ways. 
18. Nielsen M, Tomaselli K: Over-imitation in Kalahari Bushman - children and the origins of human cultural cognition. Psychol Sci 2010, 21:729-736.

Children from a small-scale non-literate culture, just as children from Western industrialized cultures, copy the irrelevant actions of a demonstrator.

19. Nielsen M, Tomaselli K, Mushin I, Whiten A: Exploring tool innovation: a comparison of Western and Bushman children. $J$ Exp Child Psychol 2014, 126:384-394.

20. Heyes CM, Frith C: The cultural evolution of mind reading. Science 2014, 344:1243091.

21. Thornton AN, Raihani NJ: The evolution of teaching. Anim Behav 2008, 75:1823-1836.

22. Csibra G, Gergely G: Natural pedagogy. Trends Cogn Sci 2009, -• 13:148-153.

A thorough and highly readable introduction to natural pedagogy theory in which the authors outline its various aspects and empirical support for them.

23. Kruger A, Tomasello M: Cultural learning and learning culture. In Handbook of Education and Human Development: New Models of Teaching, Learning, and Schooling. Edited by Olson D. Cambridge: Blackwell; 1996:369-387.

24. Butler LP, Markman EM: Preschoolers use intentional and

- pedagogical cues to guide inductive inferences and exploration. Child Dev 2012, 83:1416-1428.
Basic demonstration that children learn differently when they just experience an adult doing something and when the adult teaches them to do it - in which case they see what they are learning as more generalizable.

25. Bultler L, Schmidt M, Buergel J, Tomaello M: Young children use pedagogical cues to modulate the strength of normative inferences. $\mathrm{Br} J \mathrm{Dev}$ Psychol 2015. (in press).

26. Flynn E, Whiten A: Cultural transmission of tool use in young children: a diffusion chain study. Soc Dev 2008, 17:699-718.

27. Tennie C, Walter V, Gampe A, Carpenter M, Tomasello M: Limitations to the cultural ratchet effect in young children. $J$ Exp Child Psychol 2014, 126:152-160.

28. Köymen B, Lieven E, Engemann DA, Rakoczy H, Warneken F,

- Tomasello M: Children's norm enforcement in their interactions with peers. Child Dev 2014, 85:1108-1122.

Children teach other children the right way to do things.

29. Bonawitz E, Shafto P, Gweon H, Goodman ND, Spelke E, Schulz E:

- The double-edged sword of pedagogy: instruction limits spontaneous exploration and discovery. Cognition 2011 , 120:322-330.

Counterintuitive demonstration that children take what they are taught as THE way to do it - to the point that they ignore other possible ways to do it.

30. Rogoff B: The Cultural Nature of Human Development. New York: Oxford U. Press; 2003. 